\title{
Comparing visual counts of coral reef fish: implications of transect width and species selection
}

\author{
Alistair J. Cheal* , Angus A. Thompson \\ Australian Institute of Marine Science, PMB No. 3, Townsville, Queensland 4810, Australia
}

\begin{abstract}
We compared fish count data derived simultaneously from visual censuses of transects of different width for a wide range of species on 3 coral reefs within the Great Barrier Reef, Australia. The relationships of count data from non-pomacentrid families between transects 10 and $5 \mathrm{~m}$ wide and pomacentrid genera between transects 2 and $1 \mathrm{~m}$ wide were found to be strongly linear, with correlation coefficients of 0.94 and 0.98 respectively. The strength of both relationships was not significantly compromised by differences among selected taxa or benthic habitats. As such, comparison of data collected from different transect widths was considered feasible after application of conversion factors derived from the linear relationships. We suggest that the use of experimentally derived conversion factors may be applicable for other researchers faced with problems of data comparison across studies where different transect dimensions have been used. Density estimates from wider transects were 22 to $26 \%$ less than estimates from narrower transects for the majority of taxa. The precision (coefficient of variation) of density estimates did not vary significantly between transect dimensions, however precision varied greatly between species, genera and families, with values ranging from 0.18 to 0.85 . Transect width and the behaviour, habitat specificity and number of target fish taxon are implicated as important contributors to variation in the accuracy and precision of visual census data. We re-stress the need for methodological pilot studies as precursors to visual census studies of reef fish.
\end{abstract}

KEY WORDS: Coral reef fish $\cdot$ Transect width $\cdot$ Density $\cdot$ Precision $\cdot$ Visual census

\section{INTRODUCTION}

Since its inception in the 1950s (Brock 1954), underwater visual census has become the most accepted method for the non-destructive estimation of reef fish abundance. Increasingly, visual census data is being used as a basis for conservation strategies and to assess reef fish stocks for fishery management practises (Craik 1981, Russ 1985, Bellwood 1988, Bellwood \& Alcala 1988, Buckley \& Hueckel 1989, Samoilys \& Carlos 1992). Such management decisions necessarily should be based on the most accurate estimations of fish density. The suitability and limitations of various forms of the visual census technique for the accurate and precise estimation of reef fish abundance have been reviewed (Russel et al. 1978, Sale 1980, Thresher \& Gunn 1986) and assessed (Sale \& Douglas 1981,

·E-mail: a.cheal@aims.gov.au
Brock 1982, Sanderson \& Solansky 1986, Bellwood 1988, Greene \& Alevizon 1989, St John et al. 1990). The visual survey of belt transects by trained divers is one of the most commonly used and accepted methodologies to gain reef fish density estimates where a quantitative description of change in density over space and time is required (Sanderson \& Solansky 1986).

A number of biases may influence the accuracy and precision of density estimates when using the belt transect technique. Observer biases (including swim. ming speed, distance from the substratum and search technique) can generally be reduced by training (Sale \& Sharp 1983, Thompson \& Mapstone 1997), whereas biases induced by the distribution and habits of fishes being counted will vary with size and placement of transect units. Historically a wide variety of transect dimensions have been used, as reviewed by Sale \& Sharp (1983) with later examples including: Choat \& 
Ayling (1987), who used $50 \times 10 \mathrm{~m}$ (length $\times$ width) transects to assess reef fish abundance; Kingsford \& MacDiarmid (1988), who used transects measuring 25 $\times 12 \mathrm{~m}$ for assessing densities of planktivorous fish; Carpenter (1990), who used transects $155 \times 2 \mathrm{~m}$ for counts of herbivorous fish; and Chua \& Chou (1994), who used $150 \times 6 \mathrm{~m}$ transects to count a wide variety of coral reef species. Presumably these sampling units were chosen to compensate for the scales of patchiness in the distribution of target species. However, few studies have dealt specifically with the effects of transect width on visual estimates of fish abundances. Sale \& Sharp (1983) and Mapstone \& Ayling (1993) both noted a trend for increased density estimates from narrower transects. Fowler (1987) and McCormick \& Choat (1987) reported no effect of variable transect width on density estimates although the precision of those estimates did vary. These contradictory results suggest the need for an educated choice of transect width for the study in question and also question the validity of data comparison between studies in which different transect dimensions have been used.

Due partly to the sheer variety of transect dimensions in use, comparisons of data between studies have often been discounted. However, there is a need for large-scale data sets which allow assessment of longterm temporal and spatial changes in fish populations. Such information is necessary for the most thorough understanding and educated management of coral reef fishes. Unfortunately, the gathering of this data is often outside the logistic and financial bounds of most studies. As such, the ability to compare appropriate historical transect-based data sets with recent data for like taxa would prove both useful and cost effective if the problem of comparison across differing transect dimensions could be circumvented. Attempts to assess the validity of comparing fish abundance data derived from different methods are not evident in the literature.

Here we present the results of a field study designed to test the relationships between fish abundance counts derived from different transect widths by comparing simultaneous fish counts from 5 and $10 \mathrm{~m}$ wide transects and 1 and $2 \mathrm{~m}$ wide transects for selected non-pomacentrid and pomacentrid fishes respectively. The first aim of this study was to derive valid conversion factors, thereby allowing comparisons of fish data gathered using transects of different width. This study was initiated originally to address the problems of comparing temporal data within a long-term monitoring program in which transect widths were changed part way through the project. However, we believe that the ability to compare data from different transect dimensions may be a cost effective vehicle for broad temporal and/or spatial comparisons among other existing databases. Secondly, this study's inclusion of a wider range of taxa than has been utilised in other transect dimension comparisons allowed a discussion of the implications of the number, habit and conspicuousness of target fish species on the accuracy and precision of visual census data derived from different transect widths.

\section{MATERIAL AND METHODS}

Study site. This study was carried out on 3 reefs (Myrmidon at $18^{\circ} 15^{\prime} \mathrm{S}, 147^{\circ} 23^{\prime} \mathrm{E}$, Davies at $18^{\circ} 48^{\prime} \mathrm{S}$, $147^{\circ} 40^{\prime} \mathrm{E}$ and Rib at $18^{\circ} 28^{\prime} \mathrm{S}, 146^{\circ} 53^{\prime} \mathrm{E}$ ) in the Townsville sector of the Great Barrier Reef, Australia. Each reef had a broadly different structural environment in relation to coral cover, reef slope and general topographic complexity but shared relatively clear water with visibility greater than $12 \mathrm{~m}$. At each reef, fish counts were conducted at 3 sites along sections of continuous reef front slope at depths ranging from 4 to $9 \mathrm{~m}$. Each site contained five $50 \mathrm{~m}$ long transects running parallel to the reef crest. Transects were permanently marked with metal star pickets at either end and metal rods at $10 \mathrm{~m}$ intervals along the midline to clearly demarcate the transect path.

Target species. A total of 125 species from 8 families and 71 species from 12 genera comprised the target list for non-pomacentrid and pomacentrid fishes respectively (Halford \& Thompson 1994). Fish in the 0+ year class, as estimated from fish size and knowledge of recruitment seasons, were excluded from counts due to their often cryptic habits. The taxa included in this study (all easily identified underwater and largely noncryptic) represent a core group of species highly suited to the visual census technique as synthesised from $3 \mathrm{yr}$ of prior study (Oliver et al, 1995).

Sampling methods. All sites at each reef were censused on 2 separate days. The general procedure for non-pomacentrid surveys at each site involved 2 experienced observers swimming side by side along the central transect line counting fish to 5 or $2.5 \mathrm{~m}$ either side of the midline for the 10 or $5 \mathrm{~m}$ wide transects respectively. A minimum of bias between the 2 observers was assumed, based on comparative tests of density and size class estimates undertaken previously by the 2 observers (Thompson \& Mapstone 1997). An assistant swam approximately $15 \mathrm{~m}$ behind the observers while laying a tape measure over the substratum along the centre line of the transect. On completion of the 5 transects in which non-pomacentrid fishes had been counted, the observers returned along the same transects (which were now marked with a tape along the centre line), undertaking counts of pomacentrid fishes. For these counts the observers 
swam single file (due to space limitations) along the lower edge of the tape and counted fish occurring in a 2 or $1 \mathrm{~m}$ strip up the reef slope from the tape. Swimming speeds varied between 7 and $8 \mathrm{~m} \mathrm{~min}^{-1}$

To remove possible confounding effects between observers and transect width the observers alternated between 10 and $5 \mathrm{~m}$ wide and 2 and $1 \mathrm{~m}$ wide counts, respectively, at consecutive sites. As a result, after a $2 \mathrm{~d}$ period on each reef, both observers had estimated fish abundance at each site using all 4 transect widths. In order to reduce observer bias further, at the end of every transect each observer identified an object estimated to lie at the outer edge of the transect. The perpendicular distance between this object and the transect midline was then measured, thus providing the observers with a frequent reference to the desired transect boundaries. In addition, for the 2 vs $1 \mathrm{~m}$ comparisons, after the 3rd transect at each site, the observers exchanged position to alleviate any biases related to leadership effects.

Data organisation. Results gained from the first transect of each site (for both 10 vs $5 \mathrm{~m}$ and 2 vs $1 \mathrm{~m}$ studies) were not included in subsequent analyses. These first transects were treated as orientations to allow the observers to 'get their eye in' while changing over to the new transect width. Due to low numbers of many species, abundance data for each species were pooled to the level of site and only analysed if 3 or more fish were present. As a result, on each day 3 pairs (i.e. 1 pair for each of the 3 sites) of count data for the 5 vs $10 \mathrm{~m}$ and 1 vs $2 \mathrm{~m}$ comparisons were available, allowing a maximum of 18 possible comparisons for each species. All data were transformed $\left(\log _{10} x+1\right)$ prior to analysis in order to reduce heterogeneity of variances and to aid normalisation of skewed data sets.

Density estimates. Comparisons of density estimates (number of fish per $100 \mathrm{~m}^{2}$ ) from different transect widths were only made for species, genera and families for which a minimum of 6 pairs of density estimates had been recorded across all reefs. Paired $t$-tests were conducted for each taxonomic group to assess the significance of observed density differences due to transect width.

Conversion factor analyses. Data were pooled to family level for non-pomacentrid fish and genus level for pomacentrid species to obtain reasonable sample sizes. In order to convert abundance data from $10 \mathrm{~m}$ or $2 \mathrm{~m}$ wide transects to expected values from $5 \mathrm{~m}$ or $1 \mathrm{~m}$ wide transects, respectively, over a wide range of reefs, a number of requirements should be validated. First, the relationship between abundance data from 5 and $10 \mathrm{~m}$ and 1 and $2 \mathrm{~m}$ wide transects should be linear and therefore not influenced by density of fish. Second, this linear relationship should not vary significantly between reefs or fish taxa. In order to assess homogeneity of slopes and intercepts for different reefs and fish taxa a general linear model of the form $\ln (y)=\ln (\alpha)+\beta \ln (x)+\ln (\varepsilon)$ was used, where $y$ is the response ( $5 \mathrm{~m}$ or $1 \mathrm{~m}$ count), $x$ is the explanatory variable ( $10 \mathrm{~m}$ or $2 \mathrm{~m}$ count), $\alpha$ and $\beta$ represent parameters which may vary with reef and taxon, and $\varepsilon$ represents the model error term.

Precision estimates. In order to assess the precision of density estimates, coefficients of variation (CV, SD/ mean) were calculated daily for each reef using density estimates derived from the 3 replicate sites at each reef. Analyses were conducted only on those taxa which were sufficiently abundant to allow at least 3 estimates of precision over the $6 \mathrm{~d}$ of the study. Precision estimates were calculated at the level of species, family (5 vs $10 \mathrm{~m}$ analysis) and genus ( 1 vs $2 \mathrm{~m}$ analysis). Paired $t$-tests were used to compare coefficients of variation derived from the different transect widths.

\section{RESULTS}

\section{Density comparisons}

A total of 86 species from 9 non-pomacentrid families were recorded from the 5 vs $10 \mathrm{~m}$ study and 45 species from 12 pomacentrid genera were recorded from the 1 vs 2 m study. Density estimates were significantly different (paired $t$-test, $\mathrm{p}<0.05$ ) between 5 and $10 \mathrm{~m}$ transect widths for all selected non-pomacentrid species and families with the exception of the family Siganidae (Table 1). As indicated by percentage changes in density (Fig. 1), density estimates were consistently lower from the $10 \mathrm{~m}$ wide transects, with a mean percentage reduction in density ( $\pm 1 \mathrm{SE}$ ) from 5 to $10 \mathrm{~m}$ widths of $25.5 \pm 1.94 \%$ at species level and $25.7 \pm 2.11 \%$ at family level. Results for the pomacentrid species and genera (Table 1) were more variable but the majority of taxa exhibited significantly lower densities on wider transects (Fig. 1). Species within 2 genera, Chromis and Chrysiptera, exhibited different density relationships between 1 and $2 \mathrm{~m}$ transects, with Chromis atripectoralis, Chromis chrysura and Chrysiptera rollandi showing no significant differences and Chromis margaritifer and Chrysiptera talboti showing significantly lower densities on wider transects. The genus Chromis and Neopomacentrus azysron showed no significant density differences. The mean percentage reduction in density $( \pm 1 \mathrm{SE})$ from 1 to $2 \mathrm{~m}$ transect widths for those groups showing significant differences was $24.6 \pm 1.35 \%$ at species level and $22.2 \pm$ $2.50 \%$ at genus level. In no cases (in both the 5 vs $10 \mathrm{~m}$ wide and 1 vs $2 \mathrm{~m}$ wide transect studies) were significantly greater densities derived from the wider transects. 


\section{Conversion factors}

Those families or genera which exhibited significant density differences between transect widths were used to estimate a conversion factor. The other taxa which exhibited no significant density differences (family Siganidae and genera Chromis, Chrysiptera and Neopomacentrus) were considered inappropriate for the ultimate application of a conversion factor due to differing species trends within a genus or relatively high variances.

Table 1. Results of paired $t$-test analyses between density data derived from 5 and $10 \mathrm{~m}$ and 1 and $2 \mathrm{~m}$ wide transects, for selected families, genera and species Values in bold type indicate significant $(p<0.05)$ differences

\begin{tabular}{|c|c|c|c|c|}
\hline & Species & No. of pairs & $t$-value & $\mathrm{p}$ \\
\hline \multicolumn{5}{|l|}{5 vs $10 \mathrm{~m}$ analysis } \\
\hline \multirow{4}{*}{ Acanthuridae } & & 18 & 7.03 & 0.000 \\
\hline & Acanthurus nigrofuscus & 7 & 2.98 & 0.025 \\
\hline & Ctenochaetus spp. & 17 & 6.51 & 0.000 \\
\hline & Zebrasoma scopas & 11 & 3.00 & 0.013 \\
\hline \multirow[t]{4}{*}{ Chaetodontidae } & & 18 & 9.19 & 0.000 \\
\hline & Chaetodon baronessa & 8 & 5.03 & 0.002 \\
\hline & Chaetodon rainfordi & 10 & 5.18 & 0.001 \\
\hline & Chaetodon trifasciatus & 9 & 3.57 & 0.007 \\
\hline Labridae & & 15 & 3.58 & 0.003 \\
\hline \multirow[t]{7}{*}{ Scaridae } & & 18 & 6.85 & 0.000 \\
\hline & Scarus chameleon & 8 & 4.55 & 0.003 \\
\hline & Scarus frenatus & 7 & 4.72 & 0.003 \\
\hline & Scarus globiceps & 12 & 2.94 & 0.014 \\
\hline & Scarus niger & 17 & 3.96 & 0.001 \\
\hline & Scarus psittacus & 7 & 4.68 & 0.003 \\
\hline & Scarus sordidus & 17 & 4.70 & 0.000 \\
\hline Siganidae & & 7 & 2.30 & 0.061 \\
\hline \multicolumn{5}{|l|}{1 vs $2 \mathrm{~m}$ analysis } \\
\hline Genus & Acanthochromis polyacanthus & 14 & 2.54 & 0.025 \\
\hline \multirow[t]{2}{*}{ Amblyglyphidodon } & & 14 & 5.69 & 0.000 \\
\hline & Amblyglyphidodon curacao & 14 & 5.10 & 0.000 \\
\hline \multirow[t]{8}{*}{ Chromis } & & 15 & 0.91 & 0.380 \\
\hline & Chromis atripectoralis & 10 & -0.78 & 0.453 \\
\hline & Chromis chrysura & 6 & -0.22 & 0.835 \\
\hline & Chromis margaritifer & 6 & 2.82 & 0.037 \\
\hline & Chrysiptera rollandi & 6 & -0.99 & 0.368 \\
\hline & Chrysiptera talboti & 9 & 5.02 & 0.001 \\
\hline & Neoglyphidodon nigroris & 11 & 7.05 & 0.000 \\
\hline & Neopomacentrus azysron & 15 & -0.22 & 0.832 \\
\hline \multirow[t]{2}{*}{ Plectroglyphidodon } & & 10 & 4.54 & 0.001 \\
\hline & Plectroglyphidodon lacrymatus & 10 & 5.16 & 0.001 \\
\hline \multirow[t]{6}{*}{ Pomacentrus } & & 18 & 7.11 & 0.000 \\
\hline & Pomacentrus bankanensis & 8 & 3.03 & 0.019 \\
\hline & Pomacentrus Jepidogenys & 18 & 3.64 & 0.002 \\
\hline & Pomacentrus moluccensis & 12 & 5.23 & 0.000 \\
\hline & Pomacentrus philippinus & 15 & 6.10 & 0.000 \\
\hline & Pomacentrus wardi & 11 & 5.40 & 0.000 \\
\hline
\end{tabular}

Four non-pomacentrid families (Acanthuridae, Chaetodontidae, Labridae and Scaridae) and 5 pomacentrid genera (Acanthochromis, Amblyglyphidodon, Neoglyphidodon, Plectroglyphidodon and Pomacentrus) were included in the general linear model for the 5 vs $10 \mathrm{~m}$ and 1 vs $2 \mathrm{~m}$ comparisons respectively. Initial analyses with level of significance set at 0.05 revealed a significant ( $\mathrm{p}=0.015)$ family/reef interaction for nonpomacentrid fish and significant $(p=0.025)$ genus/reef interaction for pomacentrid fish. These full models gave $r^{2}$ values of 0.958 and 0.986 respectively. In order to assess the amount of variation contributed by the interactions, the analyses were rerun omitting the taxon and reef effects. The resulting $\mathrm{r}^{2}$ values were 0.94 and 0.977 respectively, still indicating an excellent linear fit to the data (Fig. 2). The observed interactions therefore only contributed 1.8 and $0.9 \%$ to the variation in relationships between 5 and $10 \mathrm{~m}$ and 1 and $2 \mathrm{~m}$ data respectively. This degree of variation is considered trivial in light of the typical sampling error involved in visual census data and as such the simpler model pooling over reefs was used. Resulting linear equations were: $\ln \left(y_{5 \mathrm{~m}}\right)=$ $-0.61+1.05 \ln \left(x_{10 m}\right)$ and $\ln \left(y_{1 \mathrm{~m}}\right)=$ $-0.33+0.98 \ln \left(x_{2 m}\right)$. The linear relationships between both the 5 and $10 \mathrm{~m}$ and the 1 and $2 \mathrm{~m}$ data sets exhibited $\beta$ values not significantly different to $1.0\left(t_{(69)}=1.59, \mathrm{p}=0.12\right.$ and $t_{(65)}=-1.23, p=0.22$ respectively). As such, slopes were back transformed based on the ratio of logged values to give conversion factor equations of : $5 \mathrm{~m}$ counts $=0.662 \times$ $10 \mathrm{~m}$ counts with $95 \%$ confidence intervals of 0.628 and 0.697 , and $1 \mathrm{~m}$ counts $=0.661 \times 2 \mathrm{~m}$ counts with $95 \%$ confidence intervals of 0.627 and 0.698 .

\section{Precision}

There were no significant differences (paired $t$-tests, $p>0.05$ ) in mean precision between 5 and $10 \mathrm{~m}$ transect widths and 1 and $2 \mathrm{~m}$ transect widths for any species, genus or family (Fig. 3). However, the actual estimates of mean precision did vary 
markedly between different taxa. From the wider transects, the least-precise estimates $(\mathrm{CV}>0.5)$ were derived from the family Acanthuridae (largely due to highly variable numbers of Acanthurus nigrofuscus between sites) and the species Scarus globiceps, while the family Chaetodontidae returned the most-precise $(\mathrm{CV}<0.2)$ estimates. For pomacentrid fishes, least-precise estimates were derived from Chromis atripectoralis, Neopomacentrus azysron, Pomacentrus philippinus and the genus Plectroglyphidodon (influenced largely by Plectroglyphidodon dicki). Most-precise estimates were obtained from Acanthochromis polyacanthus, the genus Pomacentrus and Pomacentrus moluccensis.

\section{DISCUSSION}

Use of different transect widths resulted in clearly different estimates of density, and hence different levels of count accuracy, for the majority of taxa included in this study. Such differences highlight the need for an empirical assessment of the relationship between data derived from different transect dimensions if data comparisons are required. This study has shown that it is possible to derive equations which allow the statistically valid comparison of fish abundance data collected from transects of different width. These equations are robust, being consistent across variable habitats and for a wide range of taxa Although conversion factors were derived from data at the level of family and genus in this study, conversion factors for individual species could also theoretically be derived if fish were sufficiently abundant. There are however a number of factors influencing the accuracy and precision of visual census data which must be considered before correction for transect width is applied.

Consideration of the differences in behaviour and habitat usage of those taxa considered inappropriate for our conversion factor, and those for which the factor was applied, serves to highlight certain limitations of the approach. The taxa included in conversion factor analyses (which exhibited density estimates signifi-
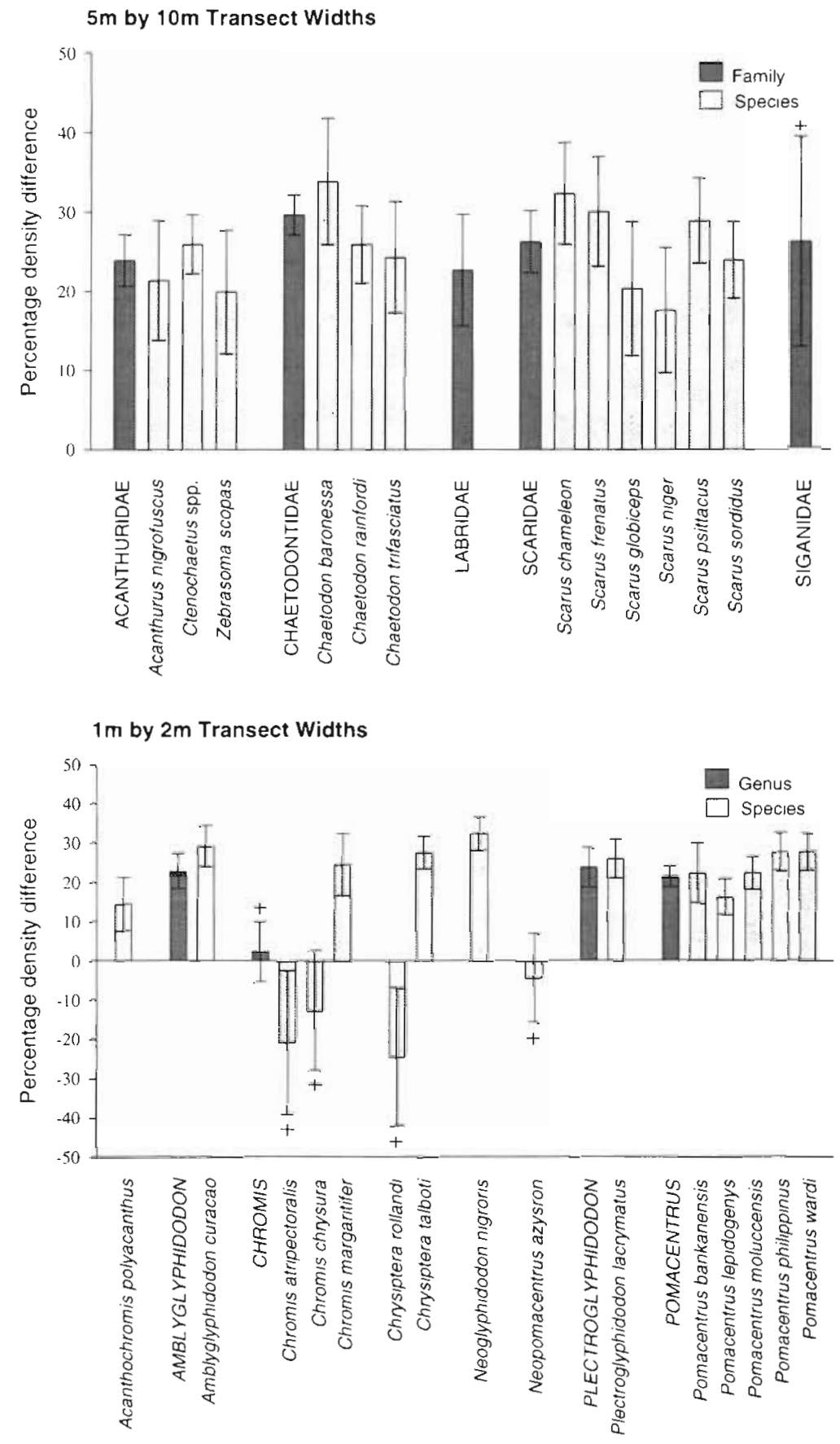

Fig. 1. Density data from wider transects $(10 \mathrm{~m}$ and $2 \mathrm{~m}$ wide) expressed as a mean percentage difference $( \pm 1 \mathrm{SE})$ of the concurrent density data from narrow transects $(5 \mathrm{~m}$ and $1 \mathrm{~m}$ wide respectively). The formula used was: $100 \%$ - (wider density counts/narrower density counts $\times 100$ ). Negative values indicate lower densities on narrower transects while positive values indicate higher densities on narrower transects. (+) Taxa where density differences are not significant $(p>0.05)$ between transect widths

cantly higher from narrower transects) comprised noncryptic, solitary to loosely aggregating species. Two pomacentrid species, Chromis margaritifer and Chry- 
siptera talboti, individually also showed similar trends, but were excluded from conversion analyses as other members of their genera exhibited different trends. Those other families or genera deemed inappropriate for conversion (due to relatively high variances or differing species trends within a genus) exhibited no significant differences in density between transects of different width. These taxa are again non-cryptic but differ in that they tend to form tightly aggregated schools. The exception was Chrysiptera rollandi which can also be considered as solitary or loosely aggregating, the difference being that it is almost exclusively associated with sand and rubble substrate as opposed to the structurally more complex hard substrata and coral communities with which the other taxa are associated. We suggest that the differences between the
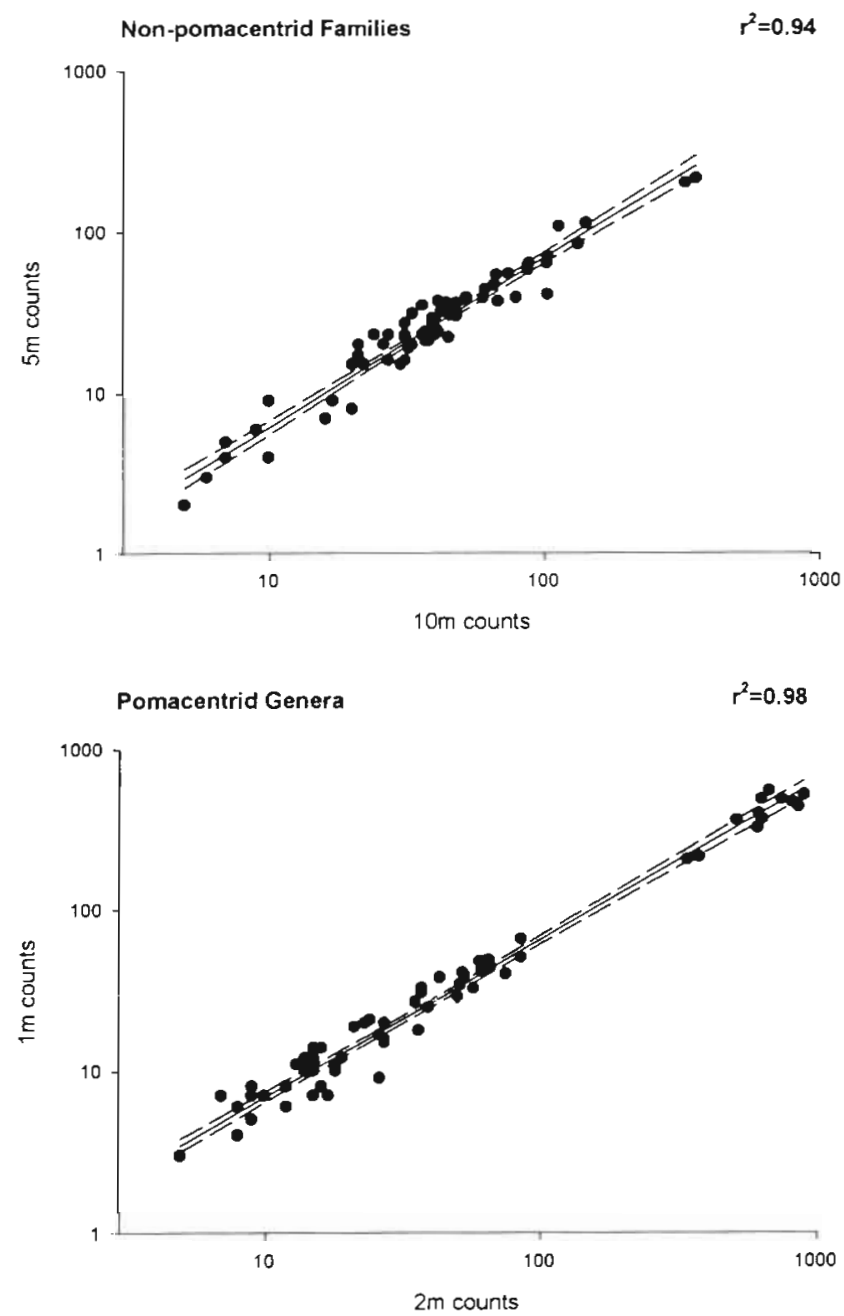

Fig. 2. Linear relationships between simultaneous counts of fish from different transect widths. Data are from 4 families for the 5 vs $10 \mathrm{~m}$ analysis and 5 genera for the 1 vs $2 \mathrm{~m}$ analysis. $95 \%$ confidence intervals and $\mathrm{r}^{2}$ values are displayed (see text for regression equations) taxa showing density changes between transects of different width and those showing no change relates directly to the conspicuousness of the component fish. Solitary or loosely aggregating species associated with the benthos are more likely to be overlooked at the wider extremes of transect width due to the increased chance of these taxa being obscured behind coral outcrops. Schooling species are more obvious as the
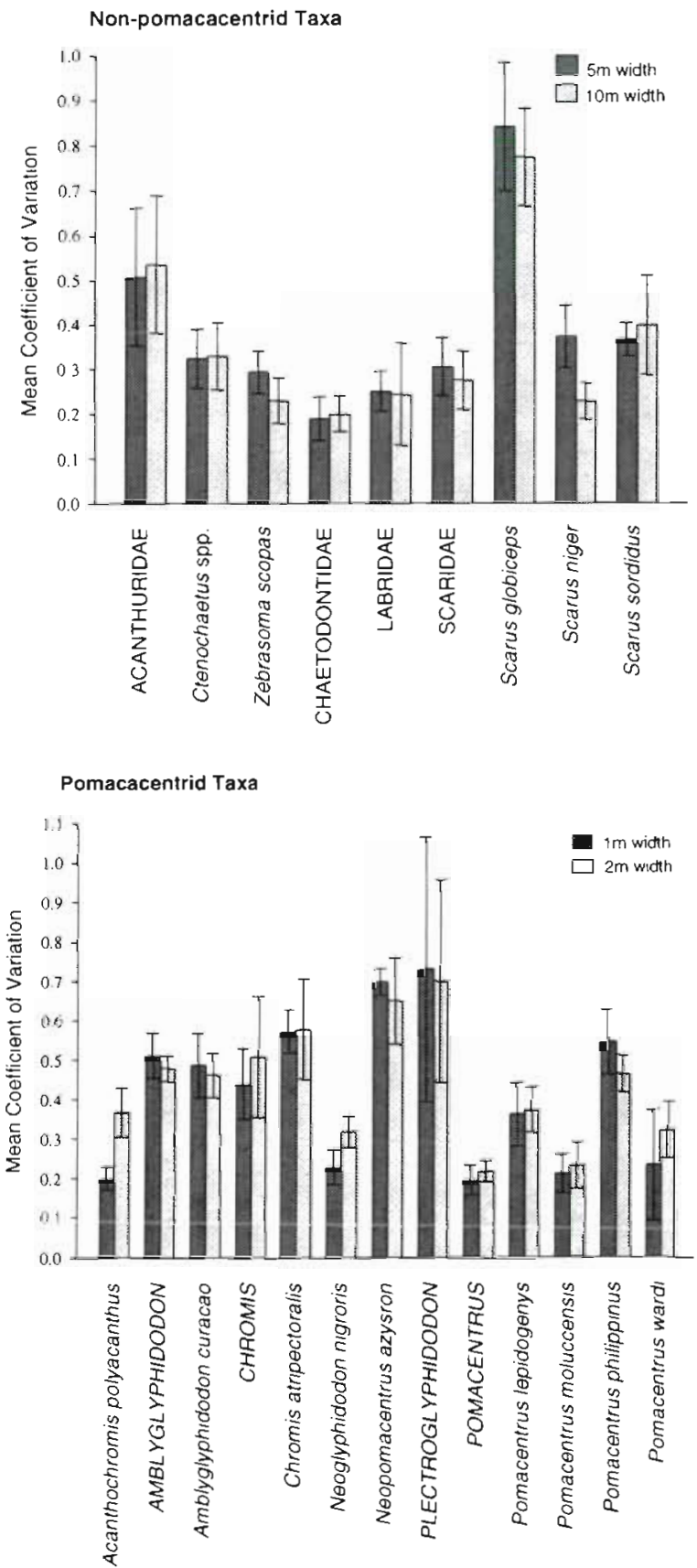

Fig. 3. Coefficients of variation (SD/mean $\pm 1 \mathrm{SE}$ ) for fish taxa density estimates from different transect widths. Taxa include species, genera and families 
school provides a much larger target image and once one fish is sighted it is unlikely that other members of the school would be overlooked. Similarly, the association of $C$. rollandi with a structurally deplete habit results in little chance that individuals would be obscured from view. In addition, the tight association with such an obvious habitat creates a search image for the species on sighting of the habitat. If these assumptions are valid then it is not that these taxa are inappropriate for the derivation of conversion factors per se, rather that relative biases between estimates from different transect dimensions require recalculation for functional groupings of taxa, sample size permitting. That there are differences between taxa in such relative biases between transect dimensions is not surprising and has been suggested previously in relation to groups of species with variably cryptic habits and appearance (Sale \& Sharp 1983, Thresher \& Gunn 1986). What is perhaps surprising is that such a high number of taxa showed very similar biases among 3 reefs of differing topographic complexity. Mapstone \& Ayling (1993), using a number of the same species included in this study, similarly reported on the remarkable consistency among fish species of the relative biases in density estimates with transect dimensions. They also found that those relative biases were unaffected by the combination of habitat and exposure conditions represented by different sites.

Whilst the influence of conspicuousness of the target species on bias in density estimates could be loosely addressed from our data, the influence on conversion factors of 2 other factors, swimming speed and number of target species included in the study, cannot be inferred from our data but deserves consideration. As swimming speeds were the same for each transect width, fish observers had more time per area to search narrower transects, resulting in a decreased chance of missing fish and possibly promoting higher density estimates from these transects. Altering swimming speed to allow equal search rates for compared transect dimensions could potentially have reduced the level of bias in density estimates. However, as Lincoln Smith (1988) points out, swimming speed is a complex issue, with speeds too fast causing underestimations and speeds too slow increasing the chance of overestimation due to the movement of fish into the transect area during counting. The swimming speeds used in this study are a result of practical experience and represent a balance between swimming slow enough for the observers to feel comfortable in their ability to sight and record numbers of target species and fast enough to reduce the confusion caused by fish movement to the transect during counting. This raises the issue of the biases induced by the number of target species included in a study. Fowler (1987) suggested that it should be more accu- rate to count a small number of fish than a large number, hence the number of species and their relative abundances may affect estimates of density gained from strip transects. The target list of species in this study was very large and, due to the visual limitations of an underwater observer, it is possible that fish were overlooked. Caughley (1977) found a similar trend in aerial surveys of mammals, reporting that, when the number of species counted at any one time increases, counts of individuals go down due to the fact that search images are constantly changing. This effect would be more marked from wider than from narrower transects when attempting to count large numbers and. varieties of fish over the same time period. It is noteworthy that the studies conducted by Fowler (1987) and McCormick \& Choat (1987), which found no differences in fish density between transects of variable width, included only 3 species and 1 species respectively.

Although precision was not significantly different between compared transect dimensions, suggesting neither transect width better addressed the heterogeneity of the target taxa's distributions, it was highly variable between species, genera and families. Leastprecise estimates of density were obtained from the family Acanthuridae (influenced largely by Acanthurus nigrofuscus), Scarus globiceps, Neopomacentrus azysron and Chromis atripectoralis, all of which characteristically form dispersed or compact schools of variable size. Bellwood \& Alcala (1988) also attributed the high variability in the estimated standing stocks of scarids to the schooling behaviour and clumped nature of 4 of the 13 scarid species monitored in their study. Plectroglyphidodon dicki and Pomacentrus philippinus preferentially inhabit colonies of thick branching acroporid corals and steep sided coral walls respectively. These 2 species returned relatively imprecise density estimates due largely to the patchy nature of their preferred habitat types. Most-precise estimates of density were obtained from the family Chaetodontidae, Acanthochromis polyacanthus, Pomacentrus moluccensis and the genus Pomacentrus. All 4 taxa share less rigid habitat associations, being more evenly distributed among transects. For those taxa exhibiting low precision, transect methodology may not be the most suitable way to derive density estimates. As pointed out by Costello et al. (1995), other visual census techniques such as timed observations are more appropriately used to compensate for the scattered schooling nature of some species.

Whilst we see experimentally derived conversion factors as viable tools to enable comparisons between suitable data derived from different transect dimensions, potential biases influencing density estimates must be explicitly considered in their calculation. We suggest that the best way of addressing this need is to 
ensure that the experience level of the observers and methods used to collect the initial data set (including number of species and swimming speed) are mirrored by those used in the sampling methodology implemented to derive the conversion factors. Furthermore, consideration should be given to the behavioural traits of the target species, looking to subdivide on the basis of conspicuousness for the calculations of conversion factors. In the process of deriving conversion factors in this study, large differences in the accuracy of density estimates between transect dimensions and precision between taxa were exposed. These results highlight the inherent difficulties in assessing densities of reef fish populations and the importance of understanding the limitations of the chosen sampling methodology. While no sampling program can hope to remove all sources of bias, we reiterate the call by a number of authors in the 1980s (Sale \& Sharp 1983, Sale et al. 1985, Fowler 1987, McCormick \& Choat 1987) for use of methodological pilot studies as a precursor to visual census studies of fish in order to ensure the provision of the most accurate and precise data.

Acknowledgements. This is Contribution No. 881 of the Australian Institute of Marine Science as part of the Institute's Long Term Monitoring Program. Comments by Hugh Sweatman and 4 anonymous reviewers improved an earlier draft of this work. We thank Hugh Layton and Daryl Smallwood of the RV 'Sirius' for logistic support in the fjeld, and Valonna Baker for data management.

\section{LITERATURE CITED}

Bellwood DR (1988) On the use of visual survey methods for estimating reef fish standing stocks. Fishbyte 6:14-15

Bellwood DR, Alcala AC (1988) The effect of a minimum length specification on visual estimates of density and biomass of coral reef fishes. Coral Reefs 7:23-27

Brock RE (1982) A critique of the visual census method for assessing coral reef fish populations. Bull Mar Sci 32:269-276

Brock VE (1954) A preliminary report on a method of estimating reef fish populations. J Wild Manage 18:297-308

Buckley RM, Hueckel GJ (1989) Analysis of visual transects for fish assessment on artificial reefs. Bull Mar Sci 44:893-898

Carpenter RC (1990) Mass mortality of Diadema antillarum II. Effects on population densities and grazing intensity of parrotfishes and surgeonfishes. Mar Biol 104:79-86

Caughley G (1977) Analysis of vertebrate populations. Wiley, London

Choat JH, Ayling AM (1987) The relationship between habitat structure and fish faunas on New Zealand reefs. J Exp Mar Biol Ecol 110:259-284

Chua CYY, Chou IM (1994) The use of artificial reefs in enhancing fish communities in Singapore. Hydrobiolgia 285:177-187

Costello MJ, Darwall WR, Lysaght S (1995) Activity patterns of North European wrasse (Pisces, Labridae) species and precision of diver survey techniques. In: Eleftheriou A, Ansell AD, Smith CJ (eds) Biology and ecology of shallow coastal waters. Olsen and Olsen, Fredensborg, p 343-350

Craik GJS (1981) Underwater survey of coral trout Plectropomus leopardus (Serranidae) populations in the Capricor- nia section of the Great Barrier Reef Park. Proc 4th Int Coral Reef Symp 1:53-58

Fowler AJ (1987) The development of sampling strategies for population studies of coral. reef fishes: a case study. Coral Reefs 6:49-58

Green LE, Alevizon WS (1989) Comparative accuracies of visual assessment methods for coral reef fishes. Bull Mar Sci 44:899-912

Halford AR, Thompson AA (1994) Visual census surveys of reef fish. Long term monitoring of the Great Barrier Reef, Standard Operational Procedure Number 3. Australian Institute of Marine Science, Townsville

Kingsford MJ, MacDiarmid AB (1988) Interrelations between planktivorous reef fish and zooplankton in temperate waters. Mar Ecol Prog Ser 48:103-117

Lincoln Smith MP (1988) Effects of observer swimming speed on sample counts of temperate rocky reef fish assemblages. Mar Ecol Prog Ser 43:223-231

Mapstone BD, Ayling AM (1993) An investigation of optimum methods and unit sizes for the visual estimation of abundances of some coral reef organisms. A report to the Great Barrier Reef Marine Park Authority, Townsville

McCormick MI, Choat JH (1987) Estimating total abundance of a large temperate-reef fish using visual strip transects. Mar Biol 96:469-478

Oliver J, De'Ath G, Done T, Williams D, Furnas M, Moran P (1995) Long term monitoring of the Great Barrier Reef. Status Report Number 1. Australian Institute of Marine Science, Townsville

Russ G (1985) Effects of protective management on coral reef fishes in the central Philippines. Proc 5th Int Coral Reef Symp 4:219-224

Russell BC, Talbot FH, Anderson GRV, Goldman B (1978) Collection and sampling of reef fishes. In: Stoddart DR, Johannes RE (eds) Coral reefs research methods. UNESCO, Paris, p 329-345

Sale PF (1980) The ecology of fishes on coral reefs. Oceanogr Mar Biol Annu Rev 18:367-421

Sale PF, Douglas WA (1981) Precision and accuracy of visual census techniques for fish assemblages on coral patch reefs. Environ Biol Fish 6:333-339

Sale PF, Jones GP, Choat JH, Leis JM, Thresher RE, Williams DMcB (1985) Current priorities in ecology of reef fishes. Search 16:270-274

Sale PF, Sharp BJ (1983) Correction for bias in visual transects of coral reef fishes. Coral Reefs 2:37-42

Samoilys M, Carlos G (1992) Development of an underwater visual census method for assessing shallow water reef fish stocks in the south west Pacific. Final Report to the Queensland Department of Primary Industries, Northern Fisheries Centre, Cairns. Australian Centre for International Agricultural Research Project PN 8545

Sanderson SL, Solansky AC (1986) Comparison of a rapid visual and strip transect technique for censusing reef fish assemblages. Bull Mar Sci 39:119-129

St John J, Russ GR, Gladstone W (1990) Accuracy and bias of visual estimates of numbers, size structure and biomass of coral reef fish. Mar Ecol Prog Ser 64:253-262

Thompson AA, Mapstone BD (1997) Observer effects and training in underwater visual surveys of reef fishes. Mar Ecol Prog Ser 154:53-63

Thresher RE, Gunn JS (1986) Comparative analysis of visual census techniques for highly mobile reef associated piscivores (Carangidae). Environ Biol Fish 17:93-116

Watson RA, Carlos GM, Samoilys MA (1995) Bias introduced by non-random movements of fish in visual transect surveys. Ecol Model 77:205-214 